\title{
Language Development, Language Disorders, and Learning Disabilities: $\mathrm{LD}^{3}$
}

\author{
Lois Bloom \\ Teacher's College, Columbia University
}

Introduction

Learning language is not easy although when one watches and listens to a young child learning to talk, it may seem easy. It may seem easy because little children use simple words, like more, Mommy, all gone, and bye bye, and not more complex words like behaviors and variation. It may seem easy because they play and laugh a lot and, when they cry, it is over such things as spilled milk. The frequent claim that children learn language quickly and easily in their first three or four years is not correct. Children work very hard at learning language.

Some children have to work much harder and for a longer time than others at learning language. A child of one to five years of age who is learning language slowly, or with particular difficulty has a learning problem. In prospect, that child can be expected to continue to have difficulty in learning in the school years. That is to say that a child who has a problem in learning language in the preschool years will be a child with a learning disability in the school years. And a child of six, seven, or eight years, or older who is having difficulty in learning reading, writing and academic skills is a child who, in retrospect, probably had a particularly hard time learning language at one, two, or three years of age - a child who was and still is a child with a learning disability.

Presented at the Annual Conference of the Orton Society, Indianapolis, November, 1979. An earlier version of this paper was presented to the New York Child Language Group, Rockefeller University, November 1977 and to a conference of the New York Association for the Learning Disabled, December, 1978. I am grateful to Margaret Lahey, Henry Lahey, Lois Hood, Karin Lifter, and Dan Stern for collaborations and conversations; to Sandy Cortelyou and Kate Garnett for their careful transcription and interpretations of the Tim data; to Janet Wootten for her help in data processing; to Margaret Jo Shepherd for reading and commenting on the drafts of this manuscript; to Edward Mysak for his generous support; and to Tim's mother for her insight. The preparation of this paper was supported in part by Research Grant BNS7807335 from the National Science Foundation.

Bulletin of The Orton Society, Vol. 30, 1980.

Copyrighe (c) 1980 by The Orton Society, Inc. ISSN 0474.7534 .

CITATION: Bloom, L. (1980). Language development, language disorders, and learning disabilities: $\mathrm{LD}^{3}$. Bulletin of the Orton Society, 30:115-133. 
There are three aspects of language learning that I will discuss in this paper. First, I will present some of the reasons why learning language is not as easy as it seems. Second, I will discuss variation in child language and include the following: the fact that individually children differ in the course of language acquisition; and the fact that the language behaviors of a particular child are variable. The variation among individuals, as well as the variation within an individual, is due in large part to the fact that learning to talk is not easy. Third, I will discuss the importance of observing and describing the behaviors of individuals rather than groups - not only for identifying the regularities, as well as the variation, in language behavior but, more importantly, for understanding a language disorder as both a learning disability and a variant of language development. In this context, I will report some preliminary analyses we have made of longitudinal, developmental data collected from a young boy whom we call Tim.

Our case study of Tim is both prospective and retrospective. We made a series of eight one-hour video-taped observations of Tim's behavior in the period of time between our first observation when he was 2 years, 9 months old, and the last observation when he was about 5 years old. Because we were observing the language behavior of a child with a language disorder, who could be expected to be a child with a learning disability in his school years, our study was a prospective one. Tim is now 8 years old, and in his third year in a classroom for children with special educational needs because of learning disabilities. Using our video-taped records of Tim's developing language behaviors from about three to five years of age, we can go back now and observe how he learned language; how his language learning varied from normal language development; and something about how difficult language learning is. Thus our study is also retrospective.

\section{There is More to Language Than Meets the Ear}

For a long time in the study of children's language, attention has been given almost exclusively to the sounds, words and sentence structures that children use when they talk. The task in learning to talk has been seen as an analytic one - infants need to learn to break into the sound stream and separate the parts. Words need to be separated into sounds so that infants can learn to combine sounds into words; and sentences need to be separated into words so that somewhat older children can learn to combine words into sentences. These analytic tasks require certain skills (at the least, perception, disscrimination, segmentation, and recognition) to enable children to learn the forms of language. Language form is the mechanism, the code, the actual 
shapes and configurations of sounds, words, and structures. Language form is what children actually say.

Forms of Language

A major emphasis in the study of language learning, then, has been on how children learn the forms of language. Some of what children need to learn about language form is represented in Figure 1.

The forms of language have been organized in Figure 1 as they are traditionally in terms of phonology, morphology and syntax. Phonology is the sound system of the language - the segments or syllables of consonants and vowels, and suprasegmental tunings of intonation, stress, and pause. Phonemes, segments and tuning do not, by themselves, carry meaning. Morphology is the collection of the smallest units of language that do carry meaning - the words in a dictionary or lexicon and inflections such as -ing, $-s$, and -er that are added to words to form other words. Syntax is the organization of words and inflections into the still larger units of language that carry meaning - the sentences of the language.

Learning the forms of language is not easy. It depends on hearing and learning to recognize recurrent aspects or regular features in what people say - even though people rarely repeat themselves or say exactly the same thing more than once. Although there are an infinite number of sentences that people can say, language form is nevertheless systematic, regular, and consistent. Learning language form depends on learning the units and the rules for the combination of units that provide for both the creativity and regularity of language. Most, if not all, of the standardized tests and instruments for assessing children's language behavior test one or another aspect of the forms of language that are schematically presented in Figure 1. These are the aspects of language that are probably most familiar to those who are concerned - as educators, clinicians, or parents - with children who have learning problems. These are the aspects of language that meet the ear.

\section{Content of Language}

At the end of the 1960's, research in chuld language began to shift toward investigation of what the forms of children's language seem to be saying and to the behaviors that accompany the words and sentences that children use in interacting with other persons. When people began to pay attention to what children were talking about, it was possible to discover and describe something about the content of their language. Language content is the meaning or semantics of messages - what we talk about. Some of what children need to learn about language content is represented in Figure 2. 


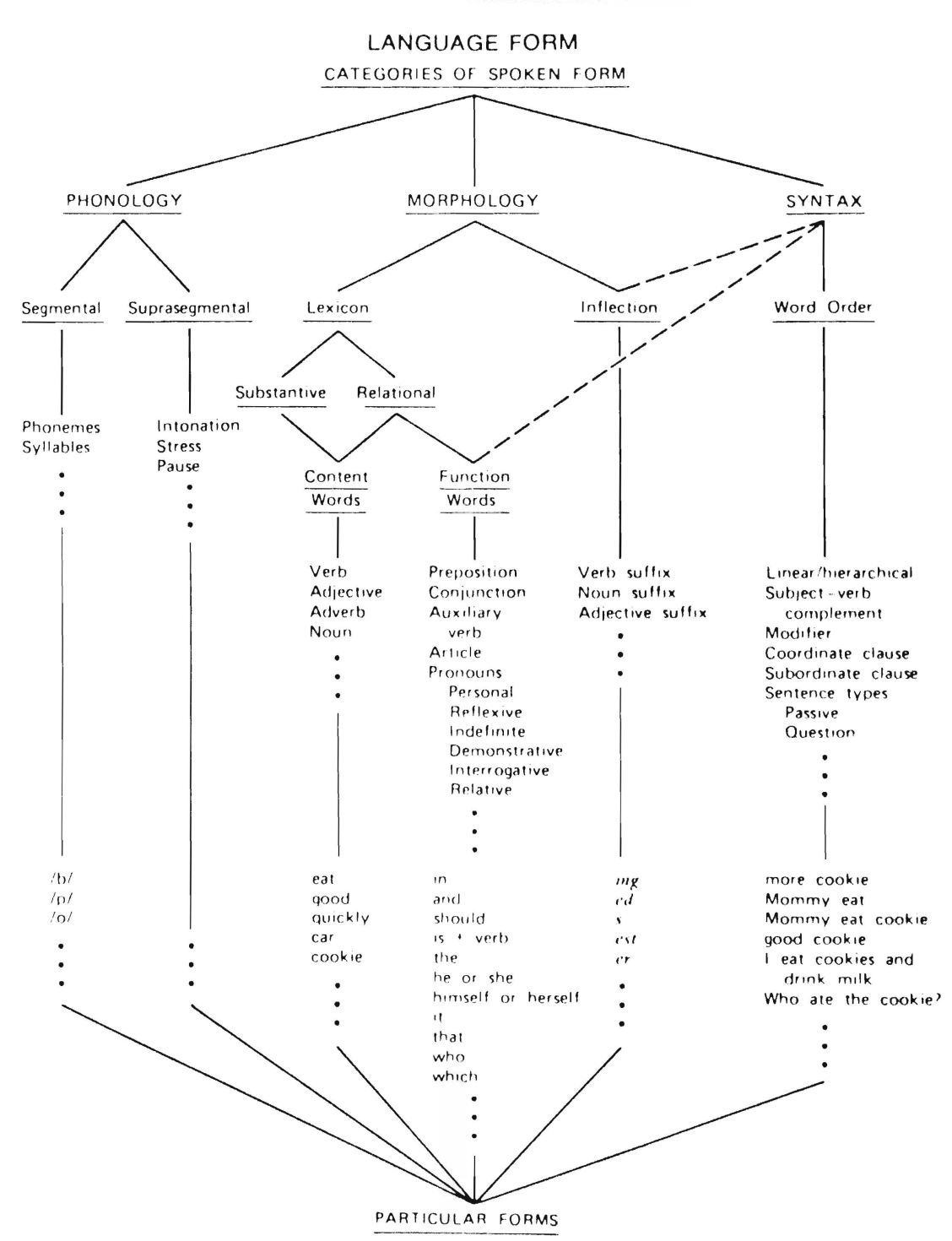

Figure 1. Reprinted with permission from Language Development and Language Disorders, by L. Bloom and M. Lahey (New York; John Wiley and Sons, 1978).

Language content has to do with what individuals know about objects, relations between objects, and about events. Children need to know, for example, that there are particular objects in the world such as Mommy, Daddy, and Chipper, the family dog (and the Empire State Building, Queen Elizabeth, etc.). They also need to know that there are classes of objects that 
LANGUAGE CONTENT AND LANGUAGE TOPICS

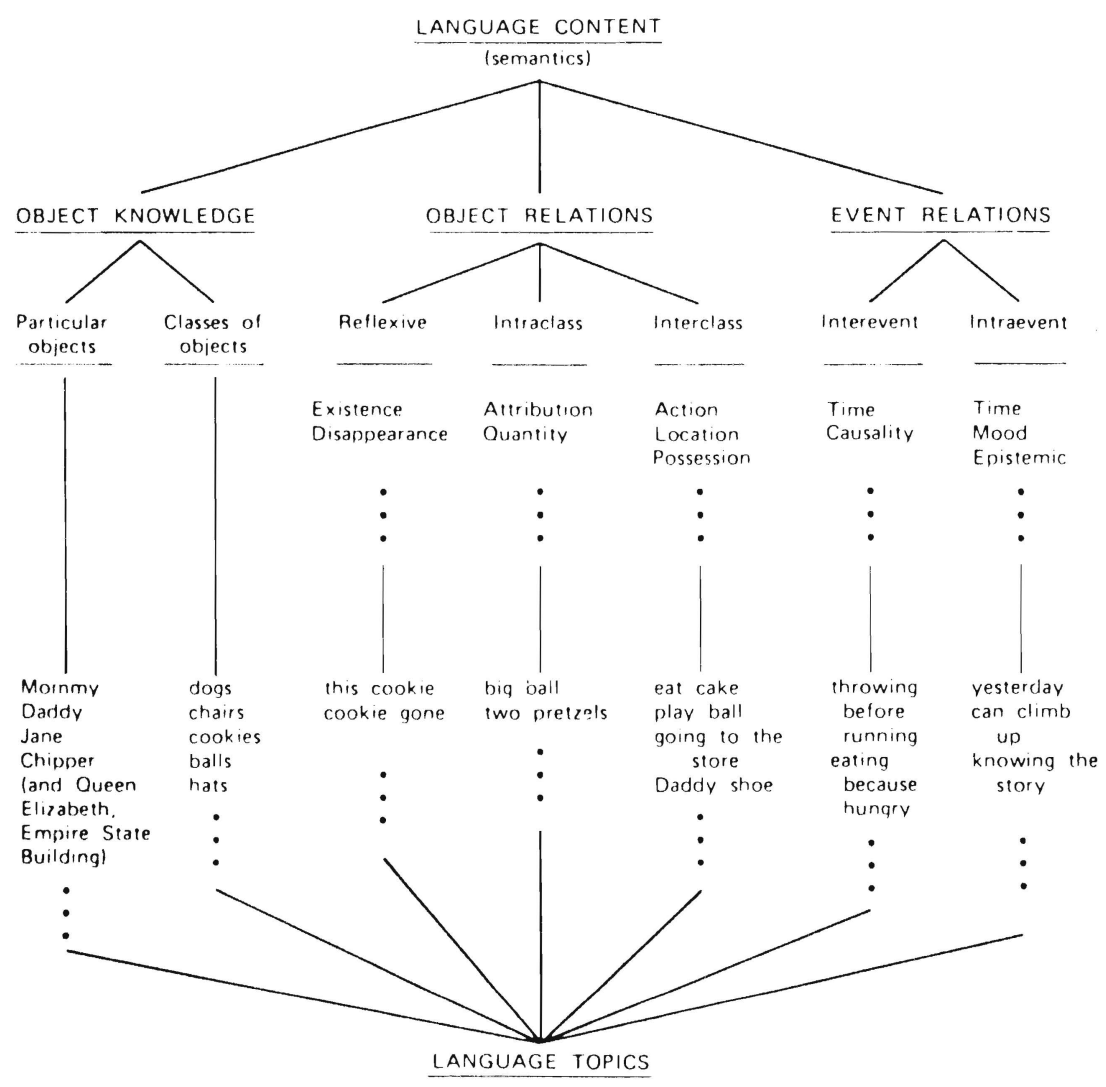

Figure 1. Reprinted with permission from Language Development and Language Disorders, by L. Bloom and M. Lahey (New York; John Wiley and Sons, 1978).

are perceptually and functionally similar to one another such as chairs, dogs, cookies, balls, etc. Children need to learn about relations among objects so that they can talk about them. There are reflexive relations of an object in relation to itself - objects exist, disappear, and recur. There are relations among objects in the same class - like objects that differ according to relative size, color, or number. There are relations between objects from different classes - one object can act on another; one object can be located on another; one object can be possessed by another.

Furthermore, children need to learn about events as well as relations between events. Such notions of content as the time an event occurs, or the mood of the speaker toward the event, or what the speaker feels or knows about the event are intra-event relations. The ways that different events relate 
to one another, or inter-event relations, have to do with notions of causality (one event is a reason for another event) and time (events can occur together or in sequence with one another), etc.

The particular objects, the particular relations, and the particular events that people talk about are the topics of language. For example, the utterances eat cookie, play ball, go store, Daddy shoe are different topics but they share a consistency or regularity in that they code the relations between objects. The fact that topics share certain features of regularity and consistency makes it possible to classify them into categories of content, as in Figure 2. There is probably an indefinite number, perhaps an infinite number, of topics that speakers can and do talk about in the same way that there is an infinite number of arrangements of forms or sentences that is possible in any language. As with language form, it is possible to classify topics according to their similarities and to form a relatively small set of categories. The categories of content represented in Figure 2 is one way topics of language can be grouped together as categories of language content.

Learning language content is not easy because language content is not so readily heard by the ear. In order to know the meaning of a message one must know something about the world of objects, events, and relations. Objects and relations in the world are, fortunately, fairly coherent and systematic; the child's task is to discover the systematic and invariant ways in which objects and events are related to one another. When these invariances or consistencies among objects are mentally represented or coded in memory, then new objects and events can be recognized and, eventually, talked about.

Use of Language

In the 1970's, as researchers and clinicians began to pay attention to how children learn to use language, there was yet another shift of emphasis in the study of children's language. Some of what children need to learn about language use is shown in Figure 3.

Children need to learn at least these two major aspects of language use: the functions or purposes of language; and the ways in which the context needs to be taken into account in order to achieve those functions. Language functions have been categorized in Figure 3 as intrapersonal and interpersonal functions. Intrapersonal functions are those functions that language serves for the individual, such as problem solving, commenting to one's self, and vocal play. Interpersonal functions are pragmatic reasons for speaking to other persons in order to obtain and maintain interaction, information, and goods and services. Halliday (1975) has called these two functions of language the mathetic and pragmatic functions, respectively. 


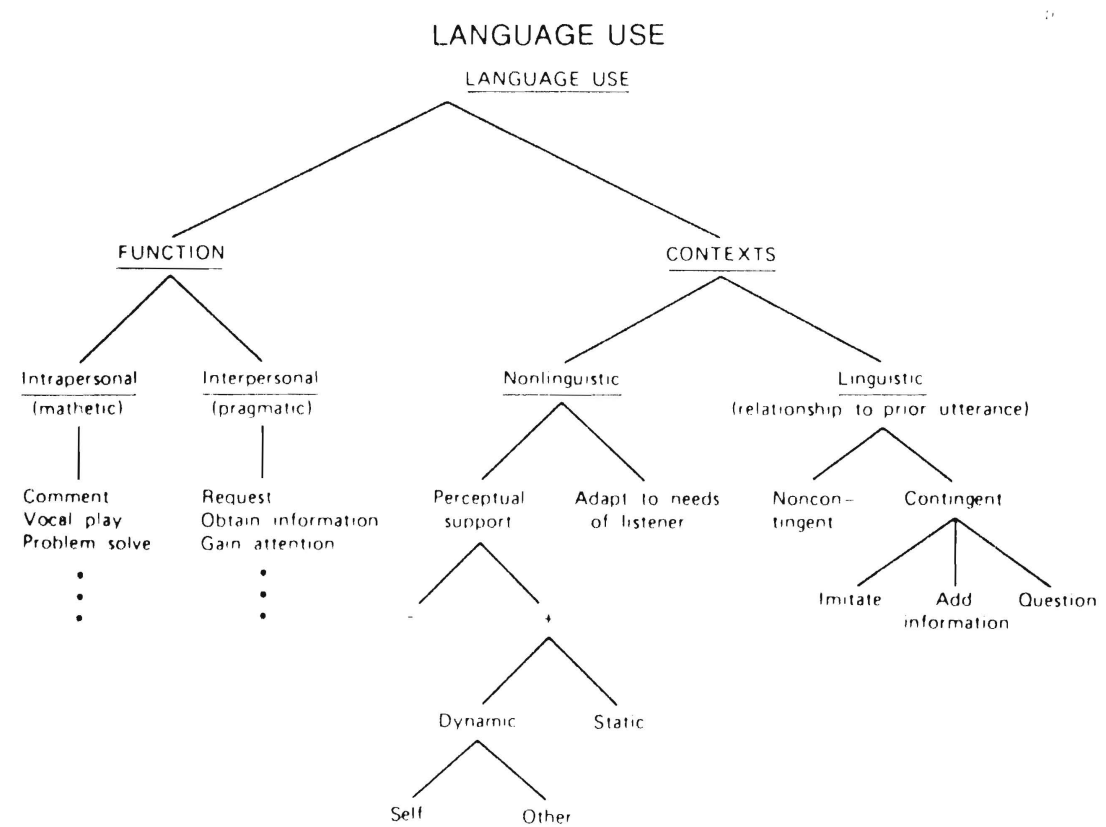

Figure 3. Reprinted with permission from Language Development and Language Disorders, by L. Bloom and M. Lahey (New York; John Wiley and Sons, 1978).

Children also need to learn to use language in relation to different kinds and amounts of support from the nonlinguistic context. When there is perceptual support from the context, it may be in the form of dynamic events that are happening or states of affairs that exist in the context as the child talks about them. Another aspect of the nonlinguistic context is the listener - different listeners need different information according to their ages, according to whether they also see what the speaker is talking about, and according to whether they already know something about what the speaker is talking about. The form and content of messages vary according to the different needs that listeners have. Thus, one talks differently to a 2-year-old child than to a 6-year-old child, and one talks differently to an adult or a teenager than one talks to a 6-year-old. If the listener can see or already knows what the speaker is talking about, then the speaker can use a pronoun as, for example, when two people are standing at a bus stop and one of them says, "It's coming." In another situation, if there is no information in the context for identifying what it is, the listener will not understand the same sentence.

Children need to learn how to adapt the form and content of their messages to the linguistic context - that is, to maintain coherent discourse. Some utterances will not be contingent on a prior utterance from someone 
else, as happens when one of the conversation partners takes the first turn, or changes the topic. But when an utterance is contingent on a prior utterance in that it shares the same topic, it may be imitative, or it may add information, or it may consist of one or another kind of question. (See Bloom, Rocissano, and Hood, 1976.)

\section{Thinking for Language Learning}

There is, then, considerably more than meets the ear for learning aspects of language form, language content, and language use. For all three of these components of language, the child's task is, in part, the same. The child must detect the regularities, similarities, and invariances in behavior - in what is seen as well as heard - in order to recognize and deal with instances of behavior (new sentences or new language topics or new contexts). In addition to detection and recognition through the ear and the eye, however, each of the three components requires the child to form inferences about behaviors, and inferences are the products of thought. Children do not only listen and watch in order to learn language; they also think to learn language.

Among the three components - form, content, and use - there are important differences in what the child needs to detect and recognize and infer. With respect to language form, the child needs to derive inferences about the underlying rules or system of language and must derive them from the regularities among the sounds, the words, and the sentence structures that people say. With respect to language content, the child needs to form inferences about the regularities and similarities in what objects do and what people do with objects. And with respect to language use, the child needs to recognize similarities in situational contexts and among listeners so as to be able to form inferences about what people know.

Integration of Language Components

It is possible to separate the components of language in order to think about language and what and how children learn about it. It is necessary, however, to remember that for the child, the different aspects of language come together in an integration of form, content, and use in development. Figure 4 illustrates the integration of these components. There is no one factor or one component of language that is more or less important than another. Learning language depends upon the interaction of form, content, and use.

To summarize, language form is the shape of messages: the sounds and sound combinations and the words and word combinations that persons say. Language content is what words and word combinations are about: the 
THE INTERACTION OF CONTENT, FORM, AND USE IN LANGUAGE

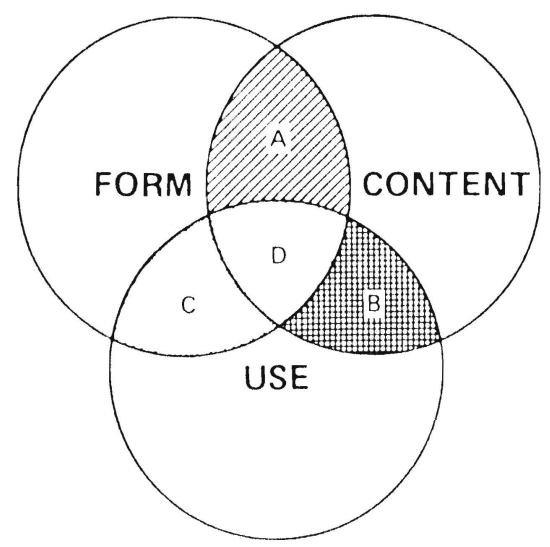

Figure 4. Reprinted with permission from Language Development and Language Disorders, by L. Bloom and M. Lahey (New York; John Wiley and Sons, 1978).

semantics or meaning of messages. Language is a means for representing information in messages, so that language form necessarily intersects with language content as children learn language. And, further, the use of language is a social act. Children learn language as a means for obtaining, maintaining, and regulating contact with other persons. The use of language depends on the goals or purposes of speaking, as well as the ways that individuals take account of the context (in particular, the needs of the listener), and how they vary the form of their messages in order to meet their goals in different speaking situations. Language development necessarily involves learning the use of linguistic forms that code elements of content for different purposes in different situations (Bloom and Lahey 1978). This intersection of language content / form/use provides a framework for the following discussion of variation in child language and the description of Tim's language behavior.

\section{Variation in Child Language}

There is a long history of research that has sought "norms" and "universals" in the language development of children. The early "count" studies of the 1930's and 1940's (see McCarthy 1954) generalized among large populations of children and resulted in normative, age-related, developmental milestones for saying words, phrases, and sentences. The research thrust in the study of child language in the 1960's was aimed at discovering the "universals" of language acquisition among children learning the same 
language, as well as among children learning different languages (see Slobin 1973). However, as impressive as the consistencies among children in language acquisition are, it has since become apparent that there is also variation among children in their language development (see, for example, Bloom 1970; Bloom, Lightbown and Hood 1975; Nelson 1975; Ramer 1976), as well as variation in language behaviors within individual children (see Bloom, Miller and Hood 1975). Variation in child language consists of the systematic ways that children are different from one another or that the behaviors of the same child can differ. Variation is as important for understanding language acquisition as is the consistency among children or the consistency within children that has been emphasized in much of the research and assessment literature.

Three kinds of variation in child language can be described. To begin with, there is developmental variation involving the understanding of both product and process. The task of describing language development includes description of behaviors at different times (the products of development) plus description of the ways that a child's behaviors are different or vary from one time to another (the process of development). There is also intersubject variation - individual differences among children in learning the forms of language - in phonology (e.g., Ferguson and Farwell 1975); in the tendency to imitate or not to imitate (Bloom, Hood and Lightbown 1974); and in the tendency to use either nouns or pronouns in relation to verbs in early sentences (Bloom, Lightbown and Hood 1975; Nelson 1975; Ramer 1976). There are also differences among children in the social use of speech (e.g., Dore 1973). Most of the variation among children that has been described so far has been variation in language form and language use; there may not be the same kind of variation among children in language content (see Bloom, Lahey, Hood, Lifter and Fiess 1980; Hood and Bloom 1979 for discussion of this point).

In addition to developmental and intersubject variation, the language behaviors of the same child differ, depending on competing lexical, grammati$\mathrm{cal}$, and discourse factors that influence what children are able to say at different times and under different circumstances (see, for example, Bloom, Miller and Hood 1975; Labov et al. 1976). Thus there is intrasubject variation, as the language behaviors of individuals can vary as a function of the interaction among the many intrinsic and extrinsic or contextual factors that contribute to language learning and language behavior.

Such variation, as it has been described, is regular, consistent, and never random. Children do not differ altogether from one another. There are either two or three patterns of variation, or a continuum along some dimen- 
sion with several children at the extremes and other children somewhere in the middle. The fact of variation among and within individuals is not surprising when one considers how enormous a task language acquisition is. Moreover, recognizing and understanding such variation in normal child language is important for recognizing that a language disorder is another form of variation in child language. It no longer appears reasonable to think in terms of stringent "norms" of language development. Children learning language normally have followed alternative routes to the same goal; there is not a single developmental pattern for all children. Variation in development does not necessarily represent abnormality. Stella Chess (1978) has recently pointed out that there is also plasticity in psychophysiological, perceptual, and cognitive development. According to Chess, such plasticity of develópment assumes great importance in attempting to understand children who approach the tasks of learning without the full complement of motor and sensory capacities.

Awareness of variation in child language and plasticity in development has come about through the study of individuals which began to replace the study of pooled data from groups of children in the 1960's and 1970's. However, preschool children with language disorders, and school-age children with learning disabilities continue to be identified clinically and educationally in terms of their deviation from a unitary norm on standardized tests of language acquisition or school achievement. As a result, there is the current debate in the literature over whether a language disorder is a delay or a deviance in development. The best way to understand language disorder as another kind of variation of child language is to study intensively the developing language of individual children who are learning language with special difficulty. Our observations and descriptions of Tim's language behavior were undertaken with this goal in mind.

\section{Tim's Language Development}

There are four aspects of Tim's language development that I can describe so far. To begin with, I will describe the content/form interactions in Tim's language, first, in terms of the kinds of words he used and their relative frequency as single-word utterances (before he began to combine words in sentences) and, second, in terms of the kinds of semantic/syntactic relations he encoded when he did begin to combine words in sentences. After describing Tim's words and the kinds of semantic'syntactic relations represented in Tim's early sentences, I will compare his developmental progression in learning words and sentences with data we have collected in our longitudi- 
nal studies of five children without language problems (Bloom 1973; Bloom, Lightbown and Hood 1975). Then I will compare the semantics of Tim's verbs with the normal development of verbs in child language that has been reported elsewhere (Bloom, Lifter and Hafitz 1980; Bloom 1978). Recognition of the importance of the development of the verb system in child language has been a major result in all of our studies of early language development. And finally, I will discuss interactions of content/form/use in terms of Tim's gaze behaviors. The discussion of gaze will be the most brief. While all of our analyses thus far are still considered preliminary, we have only impressions of the gaze data and we have not looked at them systematically as yet.

The four observations of Tim that have been processed so far for the purposes of this study are described in Table I, in terms of Tim's age, mean language utterances (MLU), numbers of utterances, and type/token ratios.

Table I

Tim's Language Samples

\begin{tabular}{ccccc}
\hline $\begin{array}{c}\text { Sample } \\
\text { Number }\end{array}$ & Age & MLU & $\begin{array}{c}\mathrm{N} \\
\text { (tokens) }\end{array}$ & $\begin{array}{r}\text { Type/ } \\
\text { Token }\end{array}$ \\
\hline & & & & \\
I & 2.9 & 1.0 & 21 & .29 \\
III & 3.1 & 1.2 & 135 & .37 \\
V & 3.5 & 2.3 & 215 & .57 \\
VII & 3.11 & 2.6 & 194 & .58 \\
\hline
\end{tabular}

Single-word Utterances

The most frequent utterance Tim used at Time I, when he was 2 years, 9 months old and saying only one word at a time, was uhoh. It occurred 15 times in the one hour observation and in such situations as: in reference to a crack in the linoleum floor; at the sound of an off-camera bump; when the cookies slithered out of the bag in his hand and onto the floor; when a crumb landed in his lap; when he spilled some juice as he bit the rim of the cup; when his constructed toy creature broke apart; when a toy leg in his grasp slipped from its peg; and after a prohibition against touching the microphone. All of the contexts for uhoh included a disjunction or disruption in Tim's activity or in the environment. Uhoh was also one of the most 
frequent words in a sample of speech from a 16 months old child, Allison, who developed language normally (Bloom 1973). Her uhoh was only one of a number of different function words that she frequently used to refer to the reflexive relations of many different objects (for example, more, there, gone, and $u p$ ). For Tim, the uhoh situation was the only relational content for which he had learned a linguistic form.

Tim said only four object words at Time I, and three of these were said in imitation: baby, juice, cookie. He also said moo in reference to the cow (see Table II).

Table II

Tim's Single-word Utterances

\begin{tabular}{cccc} 
Sample & $\begin{array}{c}\text { Function } \\
\text { Wumber } \\
\text { Wypes/Tokens }\end{array}$ & $\begin{array}{c}\text { Object } \\
\text { Words } \\
\text { Types/Tokens }\end{array}$ & $\begin{array}{c}\text { Proportion } \\
\text { Function } \\
\text { Words }\end{array}$ \\
\hline I & $2 / 17$ & $4 / 4$ & .81 \\
III & $11 / 22^{*}$ & $20 / 118$ & .19 \\
\hline
\end{tabular}

*One "action" word: up

The relationship between frequencies of function words and object words was reversed at Time III; Tim had learned more words, and object words were used more frequently than the relational words. The developmental relation between function words (such as uhoh, more, there, gone, and up) and object words (such as baby, juice and cookie) was the same for Tim from age 2.9 to 3.1 as it was for Allison from age 1.4 to 1.7. There were always more different object words (types) than there were function words (types), but there were many more function word tokens to begin with - that is, each of the few relational words occurred more frequently than did the object words to begin with. Eventually, there was a shift to more object word tokens for both children; and eventually Allison and Tim used object words more frequently than function words. There were two important differences between the two children, however. First, Tim was 17 months older and learning more slowly than Allision and, second, Tim had a narrower range of words than Allison to use for coding ideas about objects, events, and relations in the world. 


\section{Multi-word Utterances}

With respect to the semantic/syntactic relations that were represented between words in Tim's early sentences, Tim was similar to the four children (Eric, Gia, Kathryn and Peter) described in Bloom, Lightbown and Hood (1975). Existence utterances (for example, that a boy) occurred early and decreased in proportion to the other relations; action utterances that referred to movement events were more frequent than state utterances (Time V); and state utterances increased proportionately (Time VII). In several respects, however, Tim was different from Eric, Gia, Kathryn and Peter. He was 16 months older when he began to put words together (at Time III) and 20 months older when his mean length of utterance was similar (about 2.6 at Time VII). Tim's earliest multi-word utterances were instances of attribution (baby cow, big horse, other toy, daddy horse) at Time III, and there were no utterances (single or multi-word) that coded action, the most frequent relation expressed in the early sentences of Eric, Gia, Kathryn, and Peter. Finally, Tim did not code possession. (See Table III.)

Table III

Tim's Semantic/Syntactic Relations (Types)

\begin{tabular}{|c|c|c|c|c|c|c|c|}
\hline $\begin{array}{l}\text { Sample } \\
\text { Number }\end{array}$ & $\begin{array}{l}\text { Exist- } \\
\text { ence }\end{array}$ & $\begin{array}{l}\text { Attri- } \\
\text { bution }\end{array}$ & Action & $\begin{array}{c}\text { Locative/ } \\
\text { Action }\end{array}$ & $\begin{array}{c}\text { Locative/ } \\
\text { State }\end{array}$ & State & Other \\
\hline $\begin{array}{c}\text { III } \\
\mathrm{n}=12\end{array}$ & $3(.25)$ & $7(.58)$ & & & & & $2(.17)$ \\
\hline $\begin{array}{c}\mathrm{V} \\
\mathrm{n}=67\end{array}$ & $7(.10)$ & 6(.09) & $32(.48)$ & $5(.07)$ & $3(.04)$ & $4(.06)$ & $10(.15)$ \\
\hline $\begin{array}{c}\text { VII } \\
\mathrm{n}=139\end{array}$ & $9(.06)$ & $24(.17)$ & $49(.35)$ & $11(.08$ & $16(.12)$ & $16(.12)$ & $14(.10)$ \\
\hline
\end{tabular}

Thus, with respect to content/form interactions in both single and multi-word utterances, Tim's language learning was slower than normal. There were other differences that were observed, but these could best be described as variations rather than deviations from the normal data we have. Although Tim's language development varied, it was more consistent with normal language development than inconsistent. This finding complements a recent report by Mattingly (1978) who described the semantic/syntactic 
relations in the multi-word utterances of five children from $31 / 2$ to 5 years of age who had been diagnosed as children with learning problems. The children she described were using the same semantic/syntactic relations between words in their sentences as the children we have observed.

Verb Systems

All of the verbs that Tim used at Times $\mathrm{V}$ and VII were verbs that also occurred in our data from Eric, Gia, Kathryn and Peter. The action verbs that these children used were subcategorized according to their inherent aspectual

Table IV

Achievement and Activity Verbs

\begin{tabular}{|c|c|c|c|c|}
\hline & $\begin{array}{l}\text { Achievement } \\
\text { Types/Tokens }\end{array}$ & & $\begin{array}{c}\text { Activity } \\
\text { Types/Tokens }\end{array}$ & $\begin{array}{c}\text { Pro-Verbs } \\
\text { Types/Tokens }\end{array}$ \\
\hline Tim V & $7 / 56$ & $>$ & $4 / 10$ & \\
\hline Tim VII & $5 / 15$ & $\approx$ & $6 / 12$ & $3 / 7$ \\
\hline Eric $1^{\mathrm{a}}$ & $11 / 32$ & $>$ & $4 / 13$ & $4 / 15$ \\
\hline Eric $2^{b}$ & $17 / 119$ & $\approx$ & $15 / 116$ & $4 / 110$ \\
\hline Gia 1 & $13 / 45$ & $<$ & $21 / 123$ & $4 / 57$ \\
\hline Gia 2 & $15 / 64$ & $<$ & $20 / 146$ & $4 / 122$ \\
\hline Kathryn 1 & $23 / 50$ & $<$ & $23 / 91$ & $9 / 63$ \\
\hline Kathryn 2 & $14 / 131$ & $<$ & $27 / 259$ & $6 / 320$ \\
\hline Peter 1 & $7 / 58$ & $>$ & $6 / 32$ & $4 / 19$ \\
\hline Peter 2 & $14 / 81$ & $<$ & $15 / 111$ & $6 / 120$ \\
\hline
\end{tabular}

a Time $1, \mathrm{MLU} \approx 1.75$

bTime 2, MLU $\approx 2.9$ 
meanings. Aspect is the shape or contour of the event named by a verb and the following aspectual categories have been observed: achievement verbs name resultative events, with a definite end point, that are punctual or momentary in time as, for example, open, find, bump, fall; activity verbs name events that are durative, last over time, and do not have a definite result or endpoint, as, for example, cry, turn, roll, fly, sweep. When action verbs first appeared in Tim's speech at Time V, punctual, resultative achievement verbs were far more frequent than durative, nonresultative activities. (See Table IV.)

The early prevalence of achievement verbs appears to be consistent with the earlier prevalence of uhoh among Tim's single-word utterances. Uhoh events were also punctual, resultative events (e.g., spilled juice, a broken toy, etc.), and one might conclude that these aspects of content were particularly important or salient for Tim. However, recall that uhoh was one of the most frequent words of Allison, the child from whom we have early single-word data at 16 months of age. Also, activity verbs increased frm Time $V$ to Time VII in Tim's speech in numbers of types and tokens, and Tim was similar to other children we've observed in this developmental relation between activities and achievements. As can be seen in Table IV, Tim was different from Gia and Kathryn, but similar to Eric and Peter in the acquisition of these different kinds of verbs. Again, as with the semantic/syntactic relations in multi-word utterances, Tim's language behavior presents one variation (among at least two possible variations) in the relative frequency of different categories of verbs.

Gaze Behavior

This is the category of behavior that has been given the least systematic attention in the data thus far, but the developmental interactions are obviously important when one has the opportunity to view the series of eight video samples. All of the video samples were made with Tim and his mother sitting on the floor of a play room in a television studio at Teachers College. At each session, roughly the same group of toys were available for Tim and his mother to play with, and there was a snack of juice and cookies. At Time I, Tim glanced at his mother only two times in the hour, and only briefly; at Time VII, both the frequency and duration of his gazes had increased substantially.

In a recent study of Allison's gaze behaviors in a series of four video samples from 16 to 22 months of age, Schieffelin (1977) has reported the following results. The frequency of child/mother gaze in the Allison data increased $100 \%$ over the six month period. Moreover, Schieffelin observed two gaze patterns in Allison's nonlinguistic behavior: "rapid eye contact" 
which was "made and terminated within a speaker's turn" and "sustained eye contact" which was a gaze that was held beyond the boundary of at least one speaker turn. Over the four samples from 16 to 22 months there was a proportional decrease in rapid eye contact (from .70 to .55) and a proportional increase in sustained eye contact (from .30 to .45). Although the same analysis has not been applied, as yet, to the Tim data, our preliminary impressions are that both rapid and sustained eye contact began sometime after Time I and increased substantially until Time VII.

It is clear that the lack of eye contact at Time I was consistent with the general paucity of communication behaviors at the same time. Moreover, Tim's most frequent utterance at Time I, uhoh, occurred as he commented on some disjunction or disruption in his activity or the environment. Such commenting on an aspect of the context would entail gaze toward the focus of attention, and not toward a listener.

Schieffelin's observations of the developmental increase in eye contact, in both amount and kind, in relation to other communication behaviors, puts Tim's early lack of eye contact into perspective. Learning to communicate entails not only learning how to formulate ideas in messages (the intersection of form and content), but also learning the accompanying nonlinguistic skills that are required to support messages in the context of speech events (the intersection of form and content with use). Eye contact increased developmentally in Tim's behavior as he learned to talk in interpersonal communication. Children need to learn to regulate their gaze behaviors in coordination with their linguistic behaviors. Tim's gaze behavior - particularly the lack of eye contact at Time I - seems best explained as a variation in this learning, rather than a deviation from the norm.

\section{Conclusions}

To sum up, Tim's language development was delayed and it was different, but it was not inconsistent with a normal child language model. Indeed his language development seems best understood as a variant of child language, the result of difficulty in learning language. Although a variant of child language development, Tim's language behavior was also regular and consistent, and it is important to understand this. His language behaviors varied, but always in systematic and regular ways. ${ }^{1}$

'Even though Tim's language was consistent with a normal child language model, as a variant of child language, he still needed help in learning language. Tim benefited greatly from a language facilitation program, administered by his mother who became knowledgeable about language development through formal course work and regular consultation with me. 
Today Tim is an eight-year-old child with a learning disability. He is now finding it extremely difficult to learn to read and to write expressively, just as he found it so difficult to learn language when he was two, three and four years old. Reading and writing and speaking are alternative forms of language. As such, reading and writing can also be viewed in terms of how the components of language content and language use come together in intersection with language form in the course of acquisition. Content in reading and writing is what written messages are about - what they mean. The content of written messages will overlap with the content of spoken messages to be sure, but there may also be differences as well. Children also need to use reading and writing for different purposes and in different contexts. Reading a paragraph in a standardized achievement test and reading a direction for finding the television set are two such different contexts.

But although he is having difficulty, Tim is learning to read and he is learning to write, just as he did learn to talk. By definition, children with learning disabilities are children who have difficulty in learning. Thus they are having difficulty learning in schools, just as they had difficulty in learning about their worlds, in general, and learning language, in particular, at an earlier time. The prevailing assumption in the education literature is that the relation between language disorder and learning disability is one of cause and effect: learning disability in the school years occurs because of language disorder. Put another way, language is seen by many as the basis of learning disability (e.g., Wiig and Semmel 1973). However, a language disorder is a learning disability. Thus it may be more accurate and, ultimately, more productive to consider that the kinds of problems that children like Tim present are learning-based language problems rather than language-based learning problems.

$$
\text { References }
$$

Bloom, L. 1970. Language Development: Form and Function in Emerging Grammars. Cambridge, Massachusetts: The M.I.T. Press.

Bloom, L. 1973. One Word at a Time: The Use of Single-word Utterances Before Syntax. The Hague: Mouton Publishers.

Bloom, L., Hood, L. and Lightbown, P. 1974. Imitation in language development: if, when and why. Cognitive Psychology 6:380-420.

Bloom, L., 1978. The semantics of verbs in child language. Paper presented at the annual meeting of the Eastern Psychological Association, Washington, D.C.

Bloom, L. and Lahey, M. 1978. Language Development and Language Disorders. New York: John Wiley and Sons.

Bloom, L., Lahey, M., Hood, L., Lifter, K. and Fiess, K. 1980. Complex sentences: acquisition of syntactic connectives and the semantic relations they encode. J. of Child Language, in press. 
Bloom, L., Lifter, K., and Hafitz, J. 1980. Semantics of verbs, aspect, and acquisition of the verb auxiliary in child language. Language 56(2).

Bloom, Lightbown, P. and Hood, L. 1975. Structure and variation in child language. Monographs of the Society for Research in Child Development 40 (2).

Blocm, L., Miller, P. and Hood, L. 1975. Variation and reduction as aspects of competence in language development. In A. Pick (ed.). Minnesnta Symposia on Child Psychology, Vol. 9. Minneapolis: The University of Minnesota Press.

Bloom, L., Rocissano, L. and Hood, L. 1976. Adult-child discourse: developmental interaction between information processing and linguistic knowledge. Cognitive Psychology 8:521-552.

Chess, S. 1978 Blind alley, Review of Insights from the Blind, by. Selma Fraiberg. The Sciences 18:25-26.

Dore, J. 1973. The development of speech acts. Unpublished doctoral dissertation. Baruch College, City University of New York.

Ferguson, C.A. and Farwell, C.B. 1975. Words and sounds in early language acquisition. Language 51:419-439.

Halliday, M.A.K. 1975. Learning How to Mean -- Explorations in the Development of Language. London: Edward Arnold.

Hood, L. and Bloom, L. 1979. What, when, and how about why: a longitudinal study of early expressions of causality. Monographs of the Society for Research in Child Development. 44 (Serial No. 181).

Labov, W., Cohen, P., Robins, C., and Lewis, J. 1968. A study of the nonstandard English of Negro and Puerto Rican speakers in New York City. Cooperative Research Report No. 3288, Vol. 1. New York: Columbia University (ERIC ED028 423).

McCarthy, D. 1954. Language development in children. In L. Carmichacl (ed.). Manual of Child Psychology. New York: John Wiley and Sons.

Mattingly, J.M. 1978. Semantic relations and grammatical forms used by linguistically delayed children. Unpublished doctoral dissertation. Teachers College, Columbia University.

Nelson, K. 1975. The nominal shift in semantic-syntactic development. Cognitive Psychology $7(4): 461-479$.

Ramer, A. 1976. Syntactic styles in emerging language. J. of Child Language 3:49-62.

Schieffelin, B. 1977. Looking and talking: the functions of gaze direction in the conversations of a young child and her mother. Pagmatics Microfiche, Cambridge University.

Slobin, D. 1973. Cognitive prerequisites for the development of grammar. In C.A. Ferguson and D.I. Slobin (eds.). Studies of Child Language Development. New York: Holt, Rinehart, and Winston.

Wiig, E. and Semel, E. 1973. Comprehension of linguistic concepts requiring logical operations by learning-disabled children. J. of Speech and Hearing Research 16:627-636. 